See discussions, stats, and author profiles for this publication at: https://www.researchgate.net/publication/7759891

\title{
A 10-item smell identification scale related to risk for Alzheimer's disease
}

Article in Annals of Neurology · July 2005

DOl: 10.1002/ana.20533 · Source: PubMed

CITATIONS

203

10 authors, including:

Xinhua Liu

Columbia University

257 PUBliCATIONS 14,540 CITATIONS

SEE PROFILE

Michael Serby

Beth Israel Deaconess Medical Center

19 PUBLICATIONS 913 CITATIONS

SEE PROFILE
READS

483

Some of the authors of this publication are also working on these related projects:

(a)

Richard Doty

Hospital of the University of Pennsylvania

469 PUBLICATIONS 28,282 CITATIONS

SEE PROFILE

Gregory H Pelton

Columbia University

125 PUBLICATIONS 7,312 CITATIONS

SEE PROFILE

Project Cognitive Reserve View project

Project Mental health Impact of World Trade Center Attack on Asian Americans View project 
This work was supported by the Muscular Dystrophy Association (2916, D.E.), the General Clinic Research Center (M01RR020359-01, D.E., MO1-RR00084, P.C), NIH (National Center for Research Resources, K-23 RR16281-01, D.E., RR011126, J.C.), Deutch Duchenne Parent Project (G.B.) and the Beigian American Educational Foundation Inc., (G.B.).

We are grateful to Dr E. Hoffman for his support and scientific contributions, L. Morton for her invaluable coordination role within CINRG, A. Kennedy for her continuous support and interface with patients, and all parents and patients who participated in the study.

This study was first presented as Work in Progress abstract at the 128th American Neurological Association Annual Meeting, San Francisco, CA, 10/19-10/22/03.

\section{References}

1. Granchelli JA, Pollina C, Hudecki MS. Pre-clinical screening of drugs using the mdx mouse. Neuromuscul Disord 2000;10: 235-239.

2. Pulido SM, Passaquin AC, Leijendekker WJ, et al. Creatine supplementation improves intracellular $\mathrm{Ca} 2+$ handling and survival in mdx skeletal muscle cells. FEBS Lett 1998;439:357-362.

3. Brooke $\mathrm{MH}$, Griggs RC, Mendell JR, et al. Clinical trial in Duchenne dystrophy. I. The design of the protocol. Muscle Nerve 1981;4:186-197.

4. Escolar DM, Henricson EK, Mayhew J, et al. Clinical evaluator reliability for quantitative and manual muscle testing measures of strength in children. Muscle Nerve 2001;24:787-793.

5. Mendell JR, Moxley RT, Griggs RC, et al. Randomized, doubleblind six-month trial of prednisone in Duchenne's muscular dystrophy. N Engl J Med 1989;320:1592-1597.

6. Fenichel GM, Griggs RC, Kissel J, et al. A randomized efficacy and safety trial of oxandrolone in the treatment of Duchenne dystrophy. Neurology 2001;56:1075-1079.

7. Mendell JR, Province MA, Moxley RTd, et al. Clinical investigation of Duchenne muscular dystrophy. A methodology for therapeutic trials based on natural history controls. Arch Neurol 1987;44:808-811.

8. Brooke MH, Fenichel GM, Griggs RC, et al. Clinical investigation in Duchenne dystrophy: 2. Determination of the "power" of therapeutic trials based on the natural history. Muscle Nerve 1983;6:91-103.

\section{A 10-Item Smell Identification Scale Related to Risk for Alzheimer's Disease}

Matthias H. Tabert, PhD, ${ }^{1-3}$ Xinhua Liu, PhD, ${ }^{4}$

Richard L. Doty, PhD, ${ }^{5}$ Michael Serby, MD, ${ }^{6,7}$

Diana Zamora, BSc, ${ }^{1}$ Gregory H. Pelton, MD, ${ }^{1-3,8}$

Karen Marder, MD, 2,3,8,9 Mark W. Albers, MD, PhD, ${ }^{3,8,9}$

Yaakov Stern, PhD, ${ }^{1,2,3,8,9}$ and D. P. Devanand, $\mathrm{MD}^{1-3,8,9}$

University of Pennsylvania Smell Identification Test data from control subjects $(n=63)$, patients with mild cognitive impairment $(n=147)$, and patients with Alzheimer's disease $(n=100)$ were analyzed to derive an optimal subset of items related to risk for Alzheimer's disease (ie, healthy through mild cognitive impairment to early and moderate disease stages). The derived 10-item scale performed comparably with the University of Pennsylvania Smell Identification Test in classifying subjects, and it strongly predicted conversion to Alzheimer's disease on follow-up evaluation in patients with mild cognitive impairment. Independent replication is needed to validate these findings.

Ann Neurol 2005;58:155-160

Early in the course of Alzheimer's disease (AD), neurofibrillary tangles appear in olfactory-related brain regions (eg, anterior olfactory nucleus and entorhinal cortex). ${ }^{1}$ Olfactory deficits, which have been observed consistently in $\mathrm{AD},{ }^{2}$ occur early, ${ }^{3,4}$ are predictive of a future diagnosis of $\mathrm{AD}, 5,6$ and increase with disease severity. ${ }^{7,8}$

The University of Pennsylvania Smell Identification Test (UPSIT) ${ }^{9}$ is widely used in research to assess odor identification deficits, ${ }^{2,10}$ but it is less widely used in clinical practice, partly because administration takes 10

From the ${ }^{1}$ Department of Biological Psychiatry, New York State Psychiatric Institute; ${ }^{2}$ Department of Psychiatry and ${ }^{3}$ Gertrude H. Sergievsky Center, Columbia University College of Physicians and Surgeons; ${ }^{4}$ Department of Biostatistics, Columbia University, New York, NY; ${ }^{5}$ The Smell and Taste Center, University of Pennsylvania School of Medicine, Philadelphia, PA; ${ }^{6}$ Department of Psychiatry, Beth Israel Medical Center; ${ }^{7}$ Albert Einstein College of Medicine; ${ }^{8}$ Department of Neurology, Columbia University College of Physicians and Surgeons; and 'Taub Institute for Research in Alzheimer's Disease and the Aging Brain, Columbia University, New York, NY.

Received Dec 9, 2004, and in revised form Mar 29, 2005. Accepted for publication Apr 28, 2005.

Published online Jun 27, 2005 in Wiley InterScience (www.interscience.wiley.com). DOI: 10.1002/ana.20533

Address correspondence to Dr Tabert, 1051 Riverside Drive, Unit 126, New York, NY 10032. E-mail: mht35@columbia.edu 
to 15 minutes. The Brief Smell Identification Test [B-SIT], composed of 12 UPSIT items, was developed as a rapid cross-cultural screen for detecting olfactory deficits. ${ }^{11}$ To improve the clinical utility of the UPSIT for specific diseases, attempts have been made by several research groups to identify those items that best distinguish diagnostic groups such as patients with Parkinson's disease (PD) ${ }^{12,13}$ or $\mathrm{AD}^{14,15}$ from control subjects. The aim of this study was to identify an optimal subset of UPSIT items related to risk for $\mathrm{AD}$ with the goal of improving clinical applicability.

\section{Subjects and Methods}

Data from 310 subjects participating in separate studies at three medical centers were analyzed. MCI patients $(\mathrm{n}=$ $147)$ and healthy control subjects $(n=63)$ were recruited at the New York State Psychiatric Institute and Columbia University Medical Center. ${ }^{6,16} \mathrm{AD}$ patients participated at Mount Sinai Medical Center $(\mathrm{n}=56),{ }^{8}$ or in a study jointly performed at Jefferson Medical College and the Smell and Taste Center of the University of Pennsylvania $(n=44){ }^{4}$ Detailed inclusion/exclusion criteria for the respective studies have been described. ${ }^{4,6,8,16}$

Control subjects were recruited by advertisement and evaluated annually., ${ }^{6,16} \mathrm{MCI}$ patients presented with memory complaints to a Memory Disorders Center and were evaluated at 6-month intervals in a longitudinal study of early diagnostic markers of $\mathrm{AD}$. Expert clinical raters, blind to UPSIT scores, made a consensus research diagnosis at each visit $^{6,16}$ based on Diagnostic and Statistical Manual, Fourth Edition, Criteria, and National Institute of Neurological and Communication Disorders-Alzheimer's Disease and Related Disorders Association criteria. ${ }^{17}$ Patients with $\mathrm{AD}$ met criteria for a clinical diagnosis of probable $\mathrm{AD}^{17}$.

\section{Statistical Analysis}

Initially, 290 of the 310 subjects were ranked according to risk for $\mathrm{AD}$ : (1) "healthy" control subjects $(\mathrm{n}=63)$; (2) "low-risk" MCI patients, with at least 2 years of follow-up, who had not converted to $\mathrm{AD}$ within that period $(\mathrm{n}=96)$; (3) "high-risk" MCI patients who converted to $\mathrm{AD}$ within 2 years of follow-up $(\mathrm{n}=31)$; and (4) AD patients $(\mathrm{n}=100)$. Cochran-Armitage linear trend tests were applied to UPSIT data with the goal of identifying items that showed a decreasing trend in the proportion of correct smell identifications across these ordinal groups (multiple test adjusted $p<0.20$ ). UPSIT items that did not show a decreasing trend were excluded from subsequent analyses.

The remaining items were submitted to logistic regression (LR) analysis using a stepwise selection procedure. Dichotomous predictors (ie, correct vs incorrect on each UPSIT item) and a binary outcome variable (ie, control subjects plus MCI nonconverters at 2 years vs MCI converters within 2 years plus AD patients) were used. Only items that were related $(p<0.10)$ to the outcome after adjusting for all other items were retained. A second LR analysis using a likelihood score-based selection procedure ${ }^{18}$ also was applied for statistical validation. Item subsets ranging in size from one item to a set containing all items and Akaike Information Criterion ${ }^{19}$ were used to select the final set of items related to risk for $\mathrm{AD}$. To further evaluate variability in item selection, the same procedures that were used to derive the 10-item scale (Cochran-Armitage tests and stepwise LR) were applied to 100 bootstrapping samples obtained by random sampling with replacement from the original sample $(\mathrm{n}=290)$.

The ability of the 10-item scale in classifying subjects was compared with that of the UPSIT and B-SIT by calculating receiver-operating characteristic curves for each scale. A nonparametric test ${ }^{20}$ was used to assess the difference in areas under the curves (AUCs). Corresponding sensitivities and specificities for the full range of possible scores were calculated. Survival analyses were conducted on an expanded sample of MCI patients $(n=147)$ to examine the effect of the UPSIT, B-SIT, and10-item scale scores on conversion to AD (mean follow-up, 42 months). This expanded sample included 20 additional MCI patients with less than 2 years of follow-up.

Table 1. Summary of Demographic and Clinical Variables and Smell Identification Scores for Healthy Elderly Subjects and MCI and $A D$ Patients $(n=310)$

\begin{tabular}{|c|c|c|c|c|c|c|c|}
\hline $\begin{array}{l}\text { Demographic } \\
\text { Variable }\end{array}$ & $\begin{array}{c}\text { Healthy } \\
\text { Elderly } \\
(\mathrm{n}=63) \\
\text { Mean (SD) }\end{array}$ & $\begin{array}{c}\text { MCI } \\
\text { Patients } \\
(\mathrm{n}=147) \\
\text { Mean (SD) }\end{array}$ & $\begin{array}{l}\text { AD Patients } \\
(\mathrm{n}=100) \\
\text { Mean (SD) }\end{array}$ & $p^{\mathrm{a}}$ & $\begin{array}{c}\text { MCI } \\
\text { Nonconverters } \\
(\mathrm{n}=109), \\
\text { Mean (SD) }\end{array}$ & $\begin{array}{c}\text { MCI } \\
\text { Converters } \\
(\mathrm{n}=38), \\
\text { Mean (SD) }\end{array}$ & $p^{\mathrm{b}}$ \\
\hline Age (yr) & $65.71(9.38)$ & $67.43(9.85)$ & $71.72(9.54)$ & $<0.001$ & 65.59 (9.99) & $72.71(7.28)$ & $<0.001$ \\
\hline Education (yr) & $16.68(2.60)$ & $14.96(4.29)$ & $13.09(4.35)$ & $<0.001$ & $15.27(4.19)$ & $14.08(4.49)$ & 0.142 \\
\hline Sex (\% female) & 54.0 & 55.1 & 63.8 & 0.33 & 54.1 & 57.9 & .417 \\
\hline $\begin{array}{l}\text { Folstein } \\
\text { MMSE score }\end{array}$ & $29.37(0.768)$ & $27.28(3.23)$ & $19.96(5.96)$ & $<0.001$ & $27.68(3.43)$ & $26.13(2.21)$ & 0.01 \\
\hline UPSIT score & $34.86(4.18)$ & $31.22(6.45)$ & $23.72(6.48)$ & $<0.001$ & $33.02(4.68)$ & $26.05(7.96)$ & $<0.001$ \\
\hline B-SIT score & $10.60(1.53)$ & $9.56(2.21)$ & $7.04(2.62)$ & $<0.001$ & $10.12(1.70)$ & 7.95 (2.67) & $<0.001$ \\
\hline $\begin{array}{l}\text { 10-item Scale } \\
\text { score }\end{array}$ & $8.98(1.24)$ & $8.26(1.66)$ & $5.48(1.71)$ & $<0.001$ & $8.75(1.23)$ & $6.84(1.90)$ & $<0.001$ \\
\hline
\end{tabular}

\footnotetext{
${ }^{a}$ One-way analysis of variance or Fisher's exact test (sex) were conducted to compare healthy elderly, MCI patients, and AD patients.

${ }^{\mathrm{b}} t$ tests or Fisher's exact test (sex) were conducted to compare nonconverters vs converters to AD on follow-up evaluation.

$\mathrm{MCI}=$ mild cognitive impairment; $\mathrm{SD}=$ standard deviation; $\mathrm{AD}=$ Alzheimer's disease; MMSE = 30-item Mini-Mental State Examination; UPSIT $=$ University of Pennsylvania Smell Identification Test; B-SIT $=$ Brief Smell Identification Test.
} 
Table 2. Percentage Correct Smell Identifications across Four Ordinal Groups Increasing in Risk of AD and Corresponding Raw and Adjusted (multiple test adjusted $\mathrm{p}$ value $>0.20$ ) Cochran-Armitage Linear Trend Test $\mathrm{p}$ Values

\begin{tabular}{|c|c|c|c|c|c|c|c|c|c|}
\hline $\begin{array}{l}\text { UPSIT } \\
\text { Item } \\
\text { No. }\end{array}$ & $\begin{array}{l}\text { Odorant } \\
\text { Name }\end{array}$ & $\begin{array}{c}\text { Healthy } \\
\text { Elderly } \\
(\mathrm{n}=63)\end{array}$ & $\begin{array}{c}\text { MCI } \\
\text { "Low-Risk" } \\
\text { Patients } \\
(\mathrm{n}=96)\end{array}$ & $\begin{array}{c}\text { MCI } \\
\text { "High-Risk" } \\
\text { Patients } \\
(\mathrm{n}=31)\end{array}$ & $\begin{array}{c}\mathrm{AD} \\
\text { Patients } \\
(\mathrm{n}=100)\end{array}$ & $\operatorname{Raw}(p)$ & $\begin{array}{l}\text { Multiple } \\
\text { Test } \\
\text { Adjusted } \\
(p)^{\mathrm{a}}\end{array}$ & $\begin{array}{c}\text { Frequency }(\%) \\
\text { in } 100 \\
\text { Bootstrapping } \\
\text { Samples } \\
(\mathrm{n}=290 \text { each })\end{array}$ & $\begin{array}{l}\text { No. of } \\
\text { Negative } \\
\text { Regression } \\
\text { Coefficients } \\
\text { in the } 100 \\
\text { Final Item } \\
\text { Subsets }\end{array}$ \\
\hline 1 & Pizza & 91 & 81 & 61 & 61 & $<0.0001$ & $<0.0001$ & 5 & 3 \\
\hline 3 & Menthol & 92 & 85 & 84 & 48 & $<0.0001$ & $<0.0001$ & 62 & 62 \\
\hline 4 & Cherry & 98 & 88 & 81 & 59 & $<0.0001$ & $<0.0001$ & 11 & 10 \\
\hline 5 & Motor oil & 91 & 90 & 77 & 64 & $<0.0001$ & $<0.0001$ & 31 & 0 \\
\hline 6 & Mint & 95 & 87 & 74 & 55 & $<0.0001$ & $<0.0001$ & 21 & 15 \\
\hline 7 & Banana & 94 & 82 & 68 & 58 & $<0.0001$ & $<0.0001$ & 15 & 1 \\
\hline 8 & Clove & 94 & 94 & 65 & 59 & $<0.0001$ & $<0.0001$ & 88 & 88 \\
\hline 9 & Leather & 97 & 93 & 77 & 50 & $<0.0001$ & $<0.0001$ & 94 & 94 \\
\hline 11 & Onion & 89 & 82 & 68 & 56 & $<0.0001$ & $<0.0001$ & 19 & 19 \\
\hline 13 & Licorice & 97 & 91 & 84 & 61 & $<0.0001$ & $<0.0001$ & 14 & 14 \\
\hline 16 & Gasoline & 95 & 92 & 81 & 67 & $<0.0001$ & $<0.0001$ & 21 & 6 \\
\hline 17 & $\overline{\text { Strawberry }}$ & 92 & 84 & 61 & 56 & $<0.0001$ & $<0.0001$ & 61 & 60 \\
\hline 20 & Gingerbread & 84 & 70 & 55 & 49 & $<0.0001$ & $<0.0001$ & 12 & 8 \\
\hline 21 & Lilac & 94 & 94 & 81 & 62 & $<0.0001$ & $<0.0001$ & 69 & 69 \\
\hline 24 & Root beer & 95 & 91 & 74 & 68 & $<0.0001$ & $<0.0001$ & 34 & 33 \\
\hline 26 & Pineapple & 90 & 85 & 74 & 55 & $<0.0001$ & $<0.0001$ & 58 & 58 \\
\hline 29 & Wintergreen & 92 & 83 & 71 & 52 & $<0.0001$ & $<0.0001$ & 13 & 11 \\
\hline 30 & Watermelon & 87 & 85 & 71 & 61 & $<0.0001$ & $<0.0001$ & 31 & 31 \\
\hline 31 & $\frac{\text { Paint }}{\text { thinner }}$ & 95 & 92 & 81 & 60 & $<0.0001$ & $<0.0001$ & 33 & 33 \\
\hline 33 & Smoke & 92 & 83 & 52 & 55 & $<0.0001$ & $<0.0001$ & 66 & 65 \\
\hline 34 & Pine & 92 & 88 & 77 & 58 & $<0.0001$ & $<0.0001$ & 21 & 19 \\
\hline 35 & Grape & 97 & 91 & 68 & 59 & $<0.0001$ & $<0.0001$ & 39 & 39 \\
\hline 37 & Soap & 89 & 94 & 71 & 56 & $<0.0001$ & $<0.0001$ & 76 & 76 \\
\hline 38 & Natural gas & 87 & 93 & 68 & 58 & $<0.0001$ & $<0.0001$ & 51 & 51 \\
\hline 39 & Rose & 91 & 85 & 61 & 55 & $<0.0001$ & $<0.0001$ & 14 & 6 \\
\hline 40 & $\overline{\text { Peanut }}$ & 98 & 94 & 81 & 68 & $<0.0001$ & $<0.0001$ & 32 & 32 \\
\hline 2 & Bubble gum & 86 & 83 & 55 & 60 & $<0.0001$ & $<0.0001$ & 26 & 26 \\
\hline 25 & Dill pickle & 94 & 76 & 68 & 62 & $<0.0001$ & $<0.0001$ & 42 & 0 \\
\hline 19 & Chocolate & 89 & 85 & 74 & 64 & $<0.0001$ & 0.0003 & 18 & 16 \\
\hline 23 & Peach & 81 & 84 & 74 & 61 & 0.0002 & 0.0057 & 7 & 3 \\
\hline 22 & Turpentine & 83 & 80 & 58 & 62 & 0.0003 & 0.0089 & 9 & 6 \\
\hline 36 & Lemon & 71 & 68 & 55 & 49 & 0.0006 & 0.0174 & 49 & 49 \\
\hline 18 & Cedar & 84 & 79 & 74 & 63 & 0.0007 & 0.0192 & 14 & 1 \\
\hline 10 & Coconut & 79 & 79 & 45 & 64 & 0.0024 & 0.0655 & 5 & 2 \\
\hline 15 & Cinnamon & 83 & 80 & 61 & 67 & 0.0042 & 0.1068 & 6 & 1 \\
\hline 14 & $\begin{array}{r}\text { Cheddar } \\
\text { cheese }\end{array}$ & 64 & 57 & 26 & 53 & 0.0553 & 0.6938 & 7 & 7 \\
\hline 27 & Lime & 76 & 62 & 58 & 62 & 0.0737 & 0.7757 & 0 & - \\
\hline 32 & Grass & 67 & 77 & 42 & 64 & 0.0955 & 0.8473 & 1 & 1 \\
\hline 28 & Orange & 79 & 67 & 61 & 75 & 0.4558 & 0.9998 & 1 & 0 \\
\hline 12 & Fruit punch & 43 & 38 & 29 & 56 & 0.9800 & 1.000 & 0 & - \\
\hline
\end{tabular}

Bolded odorants comprise the 10-item scale. Italicized and underlined items occur in the B-SIT. The four bolded, italicized and underlined items occur in both the B-SIT and the 10-item scale.

${ }^{\text {a } I t e m s ~ a r e ~ r a n k e d ~ a c c o r d i n g ~ t o ~ m u l t i p l e ~ t e s t ~ a d j u s t e d ~} p$ values. Note: The bottom five items did not show a decreasing trend across groups $(p>$ $0.20)$.

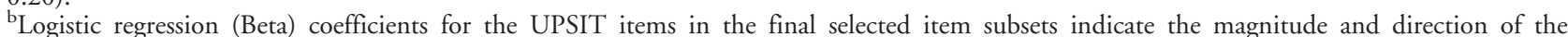
relationship between the given item and the binary outcome (controls plus MCI nonconverters vs MCI converters plus AD patients) after adjusting for all other items in the item subset. Negative regression coefficients (frequency are listed in the table for each UPSIT item) indicated that an incorrect response on the given item after adjusting for the other items in the subset is associated with the classification of "MCI converter plus AD patient" and a correct response with the classification of "Control plus MCI nonconverter."

$\mathrm{AD}=$ Alzheimers disease; UPSIT $=$ University of Pennsyluania Smell Identification Test; MCI = mild cognitive impairment.

\section{Results}

Demographic and clinical variables and olfactory scores for the control subjects and MCI and AD patients are summarized in Table 1. Cochran-Armitage linear trend tests demonstrated that five UPSIT items did not show a decreasing trend across the ordinal groups (Table 2). These five items were excluded from further analyses.

Both LR selection procedures (stepwise and likelihood score based/Akaike Information Criterion) 
yielded the same 10 items (see Table 2). A list of selection frequencies across 100 bootstrapping samples showed that the originally selected 10 items were also the most frequently selected across the 100 final item subsets (see Table 2). Also, across the final item subsets, regression coefficients consistently indicated that an incorrect response for the 10 items, after adjusting for any of the other items in the subset, was associated with being classified as an MCI converter or $\mathrm{AD}$ patient (see Table 2). For the 290 subjects (using the same binary outcome), receiver-operating characteristic curve analyses showed that the AUC for the 10-item scale was greater than for the UPSIT (AUC: 0.908, standard error $[\mathrm{SE}]=0.018$ vs $0.882, \mathrm{SE}=0.020$, respectively, $p=0.048)$ and $\mathrm{B}$-SIT $(0.841, \mathrm{SE}=$ $0.023, p<0.001)$. A similar AUC pattern was observed when the sample was restricted to $127 \mathrm{MCI}$ subjects, classified as converters within 2 years of follow-up versus nonconverters at 2 years (10-item: $0.816, \mathrm{SE}=0.042$; UPSIT: $0.789, \mathrm{SE}=0.044$; $\mathrm{B}-$ SIT: $0.756, \mathrm{SE}=0.050)$. Sensitivities and specificities for a range of possible scores on each scale are shown in Table 3.

Age-stratified Cox proportional hazards models for the $147 \mathrm{MCI}$ patients with variable follow-up times showed that scores from the UPSIT and 10-item scale significantly predicted conversion to $\mathrm{AD}(p<$ $0.0001)$, even after adjusting for sex, education, and Mini-Mental State Examination scores. The UPSIT and 10-item scale showed maximum risk ratios (RRs) of 4.30 (score $\leq 32 ; 95 \%$ confidence interval [CI], $1.81-10.26 ; p=0.001)$ and 5.03 (score $\leq 7 ; 95 \%$
CI, 2.46-10.28; $p<0.0001)$, respectively. Controlling for the same covariates reduced the RRs (UPSIT RR: $2.52 ; 95 \%$ CI, $0.99-6.42 ; p=0.053 ; 10$-item RR: 3.94; 95\% CI, 1.79-8.67; $p<0.001)$. B-SIT scores adjusted for the same covariates also were associated with conversion to $\mathrm{AD}(p=0.059$; a cutoff score $\leq 8$ yielded a maximum RR of $2.21 ; 95 \% \mathrm{CI}$, $1.05-4.67 ; p=0.037$ ).

\section{Discussion}

Analyses yielded a 10-item scale that performed comparably with the UPSIT with indications of superiority to the B-SIT in classifying subjects with increasing risk for $\mathrm{AD}$. In an expanded sample of MCI patients with variable follow-up times, the 10-item scale and UPSIT predicted conversion to $\mathrm{AD}$ after adjusting for clinical and demographic covariates. Importantly, with the data from 290 subjects, two different statistical selection procedures identified the same 10 items. The same 10 items were also the most frequently selected items in 100 bootstrapping samples. An incorrect response on these 10 items was consistently associated with risk for $\mathrm{AD}$. These findings suggest that the 10 identified items represent an optimal subset related to risk for $\mathrm{AD}$. The greater risk associated with certain UPSIT items may be explained by AD-related pathology in olfactoryrelated brain areas that may differentially impact the neural circuitry mediating odor processing.

It should be noted that, in a previous study by our group, ${ }^{6}$ with smaller sample size $(77 \mathrm{MCI}$ patients of which 19 converted to $\mathrm{AD}$ on follow-up) and shorter follow-up (mean duration of follow-up was 20

Table 3. Sensitivity and Specificity Values for the 40-Item UPSIT, 12-Item B-SIT, and 10-Item Scale When Classifying AD Patients and MCI Converters within 2 Years of Follow-up vs MCI Nonconverters at 2 Years of Follow-up plus Controls (n = 290) and When Restricting the Sample to 31 MCI Patients Who Converted to AD within 2 Years of Follow-up vs 96 MCI Patients Who Had Not Converted to AD within 2 Years $(n=127)$

\begin{tabular}{|c|c|c|c|c|}
\hline \multirow[b]{2}{*}{ Score } & \multicolumn{2}{|c|}{$\mathrm{n}=290$} & \multicolumn{2}{|c|}{$\mathrm{n}=127$} \\
\hline & $\begin{array}{c}\text { Sensitivity } \\
(\leq \text { cutoff score })\end{array}$ & $\begin{array}{c}\text { Specificity } \\
(>\text { cutoff score })\end{array}$ & $\begin{array}{c}\text { Sensitivity } \\
(\leq \text { cutoff score })\end{array}$ & $\begin{array}{c}\text { Specificity } \\
(>\text { cutoff score })\end{array}$ \\
\hline \multicolumn{5}{|c|}{ UPSIT cutoff scores } \\
\hline 29 & 77.10 & 84.28 & 58.06 & 80.21 \\
\hline 30 & 82.44 & 81.13 & 61.29 & 77.08 \\
\hline 31 & 87.79 & 76.73 & 70.97 & 73.96 \\
\hline 32 & 91.60 & 69.18 & 83.87 & 62.50 \\
\hline 33 & 93.13 & 64.15 & 87.10 & 56.25 \\
\hline \multicolumn{5}{|c|}{ 10-item scale cutoff scores } \\
\hline 6 & 63.36 & 93.08 & 45.16 & 92.71 \\
\hline 7 & 83.21 & 89.31 & 58.06 & 87.50 \\
\hline 8 & 94.66 & 67.92 & 83.87 & 65.63 \\
\hline 9 & 97.71 & 38.36 & 96.77 & 34.38 \\
\hline \multicolumn{5}{|c|}{ B-SIT cutoff scores } \\
\hline 7 & 47.33 & 88.68 & 41.94 & 88.54 \\
\hline 8 & 65.65 & 79.25 & 54.84 & 86.46 \\
\hline 9 & 78.63 & 54.72 & 67.74 & 75.00 \\
\hline 10 & 90.08 & 27.04 & 80.65 & 48.96 \\
\hline
\end{tabular}


months), low olfaction in patients with lack of awareness of olfactory deficits was a better predictor of conversion to $\mathrm{AD}$ than low olfaction scores alone. With increased power in this study's cohort of $147 \mathrm{MCI}$ patients (of which 38 converted to AD) and with longer follow-up (mean duration of follow-up was 42 months), low olfaction scores alone, after adjusting for demographic and clinical variables, strongly predicted outcome.

For olfactory tests to be clinically useful for early detection, they must be sensitive to early pathological and functional changes, significantly add to the predictive accuracy of known demographic and clinical risk factors, and be brief. The proposed 10-item scale meets these criteria and can be self-administered by patients in 5 minutes with minimal supervision. Scoring is objective and can be performed rapidly by a trained person. The practitioner needs only to review and interpret the results in the context of a clinical workup. Pending independent replication, the 10-item scale's potential diagnostic and predictive utility make a strong case for including it as part of a standard clinical workup for patients at risk for AD.

The study has several limitations. First, although differences between the odors identified here and those identified in previous reports involving $\mathrm{AD}^{14,15}$ or $\mathrm{PD},{ }^{12,13}$ or both, can be accounted for to some degree by methodological differences (eg, sample size, patient groups, statistical approaches), the lack of consistency in optimal odors identified across studies emphasizes the need for independent replication. Second, the sample used for the item reduction analyses overlapped with the sample used to evaluate the predictive utility of the scale (ie, 127 of the 147 subjects with variable follow-up were included in both sets of analyses). This limitation further emphasizes the need for replication and validation. Specificity against other disorders such as PD also needs to be established, with neuropathological confirmation if possible. Finally, future cross-cultural validation studies will be needed to ascertain the discriminative and predictive potential of the 10-item scale outside of North America.

In conclusion, if the proposed scale's predictive accuracy for conversion from MCI to $\mathrm{AD}$ is replicated and is comparable or superior to other early markers, it may in combination with other diagnostic tests help to improve early detection of AD.

This study was supported by the NIH (National Institutes on Aging, AG17761, D.P.D.; AG08702, R.L.D.; AG17496, R.L.D.; 1K01AG21548, M.H.T.; National Institutes of Mental Health, MH50038, D.P.D.; National Institutes on Deafness and Other Communication Disorders, R01 DC04278, R.L.D.; K08 DC04807, M.W.A.).

\section{References}

1. Morris JC, Price AL. Pathologic correlates of nondemented aging, mild cognitive impairment, and early-stage Alzheimer's disease. J Mol Neurosci 2001;17:101-118.

2. Mesholam RI, Moberg PJ, Mahr RN, Doty RL. Olfaction in neurodegenerative disease: a meta-analysis of olfactory functioning in Alzheimer's and Parkinson's diseases. Arch Neurol 1998; 55:84-90.

3. Morgan CD, Nordin S, Murphy C. Odor identification as an early marker for Alzheimer's disease: impact of lexical functioning and detection sensitivity. J Clin Exp Neuropsychol 1995; 17:793-803.

4. Doty RL, Reyes PF, Gregor T. Presence of both odor identification and detection deficits in Alzheimer's disease. Brain Res Bull 1987;18:597-600.

5. Graves AB, Bowen JD, Rajaram L, et al. Impaired olfaction as a marker for cognitive decline: interaction with apolipoprotein E epsilon4 status. Neurology 1999;53:1480-1487.

6. Devanand DP, Michaels-Marston KS, Liu X, et al. Olfactory deficits in patients with mild cognitive impairment predict Alzheimer's disease at follow-up. Am J Psychiatry 2000;157: 1399-1405.

7. Murphy C, Gilmore MM, Seery CS, et al. Olfactory thresholds are associated with degree of dementia in Alzheimer's disease. Neurobiol Aging 1990;11:465-469.

8. Serby M, Larson P, Kalkstein D. The nature and course of olfactory deficits in Alzheimer's disease. Am J Psychiatry 1991; 148:357-360.

9. Doty RL, Shaman P, Dann M. Development of the University of Pennsylvania Smell Identification Test: a standardized microencapsulated test of olfactory function. Physiol Behav 1984; 32:489-502.

10. Doty RL. Odor perception in neurodegenerative disease and schizophrenia. In: Doty RL, ed. Handbook of olfaction and gustation. 2nd ed. New York: Marcel Dekker, 2003:479-502.

11. Doty RL, Marcus A, Lee WW. Development of the 12-item Cross-Cultural Smell Identification Test (CC-SIT). Laryngoscope 1996;106:353-356.

12. Hawkes CH, Shephard BC, Daniel SE. Olfactory dysfunction in Parkinson's disease. J Neurol Neurosurg Psychiatry 1997;62: 436-446.

13. Double KL, Rowe DB, Hayes M, et al. Identifying the pattern of olfactory deficits in Parkinson disease using the Brief Smell Identification Test. Arch Neurol 2003;60:545-549.

14. Serby MJ, Kalkstein D, Smith GS, Russel M. Odorant specificity in olfactory identification deficits in aging and Alzheimer's disease. Chemical Senses 1992;17:696-697.

15. Lange R, Donathan CL, Hughes LF. Assessing olfactory abilities with the University of Pennsylvania smell identification test: a Rasch scaling approach. J Alzheimers Dis 2002;4: 77-91.

16. Tabert MH, Albert SM, Borukhova-Milov L, et al. Functional deficits in patients with mild cognitive impairment: prediction of AD. Neurology 2002;58:758-764.

17. McKhann G, Drachman D, Folstein M, et al. Clinical diagnosis of Alzheimer's disease: report of the NINCDS-ADRDA Work Group under the auspices of Department of Health and Human Services Task Force on Alzheimer's Disease. Neurology 1984;34:939-944.

18. Furnival GM, Wilson BS. Regression by leaps and bounds. Technometrics 1974;16:499-511.

19. Akaike H. A new look at statistical model identification. IEEE Transactions on Automatic Control 1974;AC-19:716-723. 
20. DeLong ER, Delong DM, Clark-Pearson DL. Comparing the areas under two or more correlated receiver operating characteristic curves: nonparametric approach. Biometrics 1988;44: 837-845.

Mental Retardation and Ataxia Due to Normotriglyceridemic Hypobetalipoproteinemia

Vivienne M. Homer, PhD, ${ }^{1}$ Peter M. George, FRCPA, ${ }^{1}$ Stephen du Toit, BSc Hons.MMED, ${ }^{2}$

James S. Davidson, PhD, FRCPath ${ }^{3}$

and Callum J. Wilson, FRACP ${ }^{4}$

A 12-year-old boy with mental retardation, obesity, ataxia, and visual impairment was shown to have normal fasting plasma triglyceride but low cholesterol and vitamin E levels. Investigations indicated that he was compound heterozygous for two mutations in the apolipoprotein $\mathrm{B}$ gene $(A P O B)$, resulting in a failure to express apolipoprotein B-100, yet retain apolipoprotein B-48 production. The proband therefore was able to form chylomicrons, but not a low-density lipoprotein capable of receptor-mediated endocytosis. This resulted in chronic vitamin $\mathrm{E}$ deficiency. We suggest the term normotriglyceridemic bypobetalipoproteinemia for this easily recognizable condition.

Ann Neurol 2005;58:160-163

The apolipoprotein $\mathrm{B}$ gene $(A P O B)$ encodes two proteins: apolipoprotein B-48 (ApoB-48) and ApoB-100. ApoB-48 is formed in the intestine and is essential for the formation and recognition of dietary-derived chylomicrons. ${ }^{1,2}$ In contrast, ApoB-100 is found in the very low-density (VLDLs) and low-density lipoproteins (LDLs) of hepatic origin, and is involved in the endogenous transport of triglycerides, cholesterol, and fatsoluble vitamins. The smaller ApoB-48 polypeptide re-

From the ${ }^{1}$ Molecular Pathology Laboratory, Canterbury Health Laboratories, Christchurch; ${ }^{2}$ Diagnostic Medlab; ${ }^{3}$ Chemical Pathology, LabPlus, Auckland City Hospital; and ${ }^{4}$ National Metabolic Service, Starship Hospital, Auckland, New Zealand.

Received Mar 14, 2005, and in revised form Apr 28. Accepted for publication Apr 28, 2005.

Published online Jun 27, 2005 in Wiley InterScience (www.interscience.wiley.com). DOI: 10.1002/ana.20531

Address correspondence to Dr Wilson, National Metabolic Service, P.O. Box 872, Auckland, New Zealand.

E-mail: callumw@adhb.govt.nz sults from a tissue-specific, posttranscriptional, singlenucleotide substitution in the intestinal APOB messenger RNA that changes a glutamine codon into a stop codon at residue $21533^{3}$ The resulting polypeptide chain contains 2,152 amino acids $(264 \mathrm{kDa})$, which is $48 \%$ (hence the name ApoB-48) of the apparent molecular mass $\left(M_{\mathrm{r}}\right)$ of the $4,536(549 \mathrm{kDa})$ ApoB- 100 protein. A number of abnormally truncated ApoB proteins have been described, usually in the heterozygous state, and by convention these are referred to by this percentile system, reflecting their apparent $M_{\mathrm{r}}$ in relation to ApoB-100. ${ }^{2}$

Truncations shorter than ApoB-27 are not expressed in lipoproteins, whereas those less than ApoB-75 show little expression in LDLs. ${ }^{4-8}$ Consequently, severe homozygous mutations in the $\mathrm{N}$-terminal third of $A P O B$ result in the virtual absence of both ApoB-48 and ApoB-100 and their corresponding lipoproteins, and thus low levels of triglycerides, cholesterol, and the fatsoluble vitamins. This condition is known as hypobetalipoproteinemia and is characterized clinically by severe failure to thrive, steatorrhea, and eventually both central and peripheral neurological abnormalities. ${ }^{2}$

In marked contrast to hypobetalipoproteinemia, Malloy and colleagues ${ }^{9}$ described a patient with relatively normal concentrations of triglyceride, chylomicron, and ApoB-48 but absent or low concentrations of cholesterol, ApoB-100, and fat-soluble vitamins. Clinically, the patient had obesity and mental retardation with evidence of nerve conduction defects. This condition was called normotriglyceridemic abetalipoproteinemia, and later it was shown that it was caused by a homozygous mutation at codon 2252 in $A P O B$ that resulted in an ApoB-50 protein in addition to a normal ApoB-48 protein. ${ }^{10}$ There have been two other reports of patients with similar biochemistry. ${ }^{11,12}$ In the first case, only clinical data from infancy were reported, whereas the second article documented a family with a probable heterozygous condition and much milder clinical features. No molecular analysis was reported in the either article.

We report a patient with strikingly similar clinical and biochemical features to the original case that Malloy and colleagues ${ }^{9}$ presented, but with slightly different molecular cause in that the patient was a compound heterozygote for a null allele and a novel ApoB variant, ApoB-66. This second case confirms the condition as a distinct clinical entity, although the term normotriglyceridemic hypobetalipoproteinemia is preferred to normotriglyceridemic abetalipoproteinemia.

\section{Patient and Methods}

\section{Case Report}

The patient, a New Zealand Maori boy, presented at aged 1 year with developmental delay. At aged 2 years, he began having generalized seizures that responded well to carbamaz- 